\begin{tabular}{|c|c|}
\hline \multirow{3}{*}{ 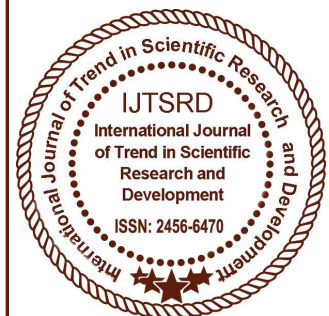 } & $\begin{array}{l}\text { International Journal of Trend in Scientific } \\
\text { Research and Development (IJTSRD) }\end{array}$ \\
\hline & International Open Access Journal \\
\hline & ISSN No: 2456 - 6470 | www.ijtsrd.com | Volume - 1 | Issue - 6 \\
\hline
\end{tabular}

\title{
Isolation, Characterization and Bioactivities of Sambucus wightiana derived Dotriacontanoic acid
}

\author{
Mudasir A Mir ${ }^{1 *}$, Insha Zahoor ${ }^{2}$, Amrina Shafi ${ }^{3}$ \\ ${ }^{1}$ Centre for Plant Biotechnology, Division of Biotechnology, Sher-e-Kashmir University of Agricultural \\ Sciences and Technology of Kashmir, Shalimar, 191121, India. \\ ${ }^{2}$ Department of Biotechnology, School of Biological Sciences, University of Kashmir, Srinagar, Jammu \\ and Kashmir, 190006, India. \\ ${ }^{3}$ Division of Biotechnology, CSIR-Institute of Himalayan Bioresource Technology, Palampur, Himachal \\ Pradesh, 170761, India.
}

\section{ABSTRACT}

The demand for naturally occurring bioactive molecules such as antioxidant, anticancer and antimicrobial properties is emerging globally. More and more natural products are being investigated to isolate and characterize the bioactive small molecules. Therefore, the current research work was undertaken to isolate and characterize bioactive compounds from leaf part of Sambucus wightiana. Various hyphenated spectral techniques such as Uv-Vis, NMR, FT-IR and MS were undertaken to investigate identity of isolated compound. The study results isolation of Dotriacontanoic acid, an important molecule that possesses fabulous medicinal properties like antioxidant, antibacterial and antioxidant.

Keywords: Sambucus wightiana, bioactivity, antioxidant, anti-microbial,NMR, FT-IR, MS

\section{INTRODUCTION}

Sambucus wightiana W. is a woody shrub with herbaceous stem of 4-5 feet, possessing pinnatifid leaves $(15-30 \mathrm{~cm})$ with 5-9 leaflets. The flat topped flower clusters are white-creamy, heavy-scented, hermaphrodite in nature which are seen during JuneJuly season \& (Polunin and Stainton, 1984; Kaul, 1997; Sharma, 2003), also its orange-reddish, edible berries are attracting ecotourists (Kaul, 1997;
Khattak et al., 2005) and it propagates via seeds. It is commonly found on heavily grazed slopes, forest floor, waysides, in gregarious clumps under semishade (light woodland) or no shade places at an altitude of 1800-2400 meters. The distribution of this species ranges from Afghanistan to Himalayan regions of Pakistan and India, commonly known as Kashmir elder or dwarf elder and is recognized with local names such as Kown in Kishtwar and Gandula in Kashmir regions of Jammu and Kashmir (Vidyarthi, 2010; Polunin, and Stainton, 1984).

The various ethno-medicinal uses attributed to Sambucus wightiana include emetic for expelling poisonous substances, to treat stomach disorders (Polunin, and Stainton, 1984), as laxative (Stewart, 1969), to treat skin diseases, also roots, leaves and berries are used for purgative purpose, root and inner bark as diuretic (Vidyarthi,2010), anti-inflammatory, expectorant, diaphoretic,, hypotensive (Ford, 1938), against foot and mouth disease in cattle (Sharma, 2003). The dye is extracted from its fruits for coloring yarn (Khattak et al., 2005) and most recently its antibacterial, antifungal activities are reported in literature (Ford, 1938). The various important phytocompounds found in different parts of Sambucus species such as Phenolics, anthocyanins, 
favanols, quercetin, chlorogenic acid, cyanidin 3sambubioside and cyanidin 3-glucoside in elderberries, quercetin, kaempferol and other glycosylated flavonoids in flowers (Ballabh et al., 2008). The presence of abundant anthocyanin content in elderberries could fetch a good commercial benefit because anthocyanins have various potential health benefits such as higher antioxidant potential compared to vitamins $\mathrm{C}$ and $\mathrm{E}$, this can be used by the food, cosmetic, and pharmaceutical industries (Ballabh et al., 2008).

The most popular technique for the herbal identification is TLC which is being used for identification in monographs of herbal medicines in most pharmacopoeias of the world due to simplicity, reproducible, requires little equipment and offers a quick analytical approach localization, isolation and subsequent characterization of bioactive compounds (Bhawna and Bharti, 2010). However, for preparative purposes and further cleaning of isolated compounds, column chromatography offers an efficient way to obtain desired pure compounds in larger quantities, it utilizes silica gel as packing material based on a two phase system where the mobile phase is an eluent \& the stationary phase is an adsorbant in the column (Melnyk et al., 2010 and Patra et al., 2012). The bioassay-guided isolation is a basic technique which has been utilized by various researchers for characterizing important biologically active natural products (Sarker et al., 2005; Alwash et al., 2013).1 Considering its rich ethno- medicinal properties and the need to discover new potential bioactive 3 molecules is emerging immensely. Therefore, current study was carried out to isolate and characterize potential bioactive compounds.

\section{MATERIALS AND METHODS}

\section{Sample Collection}

The leaf samples of Sambucus wightiana were collected from Ahribal region of Kashmir, India (2,266 $\mathrm{m}$ above sea level) and were authenticated at Centre for Biodiversity and Taxonomy, University of Kashmir herbarium (KASH) and voucher specimen was deposited with voucher number KASH-1732. The shade dried leaves were subjected to solvent extraction using methanol, extract obtained was kept in light protected bottles at $4^{0} \mathrm{C}$ for till further analysis.
Localization, isolation and purification of bioactive compounds

The standard methods for identification and isolation of biologically active compounds from plant extracts was followed (Canell, 1998).

\section{Analytical TLC}

Firstly, in order to find the best mobile phase for the separation of compounds, an analytical TLC was performed on silica pre coated aluminium sheets $(5 \mathrm{X} 10 \mathrm{~cm})$ from Macherey-Nagel \& Co. Duren Germany) using several literature based and random mobile phases. The TLC plates were air dried after developing in the respective mobile phases and then treated with iodine vapors and p-anisaldehyde universal stain $\left(10 \mathrm{ml} \mathrm{H}_{2} \mathrm{SO}_{4}+\right.$ ice cold mixture of methanol-170 $\mathrm{ml}$ and $20 \mathrm{ml}$ acetic acid $+\mathrm{I} \mathrm{ml}$ anisaldehyde) to visualize the bands (Reich, 2006), the bands were marked with pencil. The $\mathrm{Rf}$ values were calculated for each spot i.e. $\mathrm{Rf}=$ Distance spot moved/distance solvent moved.

\section{Bioautography}

The bioactive spots/bands were identified using important chromatography technique known as Bioautography i.e. Agar-overlay bio-autographic assay for antimicrobial agents (Canell, 1998; Sule et al., 2011) and antioxidant TLC assay (Sarker et al., 2005). The below procedures were followed for Bioautography Techniques:

\section{A. Agar-overlay bio-autographic assay}

1 Two sterilized TLC plates were taken (One for bioassay and as reference) and to each $10 \mu \mathrm{l}$ of sample extract was applied as a small spot and plates were developed in an appropriate mobile phase i.e.toluene:acetone:water: acetic acid (16:2:2:2) for non-polar solvents and ethyl acetate:iso-propanol:water $(65: 25: 10)$ for polar solvents.

2 TLC plates were removed from the solvent chamber and dried in an oven at $25^{\circ} \mathrm{C}$ for 7 hours so as to remove all the residual solvents.l

3 Either of the TLC plate was exposed to iodine vapors and bands were marked with pencil, the plates were later exposed outside to remove marks of iodine, any iodine.

4 The iodine free TLC plate was derivatized using universal reagent i.e.anisaldehyde-sulfuric acid. The plate is immersed in the reagent for $1 \mathrm{~s}$ then 
heated at $100^{\circ} \mathrm{C}$ for $2-5$ min. The bands were identified, marked and $\mathrm{Rf}$ values were recorded.

5 Take $200 \mu$ from respective broth cultures of two bacterial strains i.e. E.coli \& S.marcencs $\left(10^{8} \mathrm{cfu} / \mathrm{ml}\right) \&$ mixed with $35 \mathrm{ml}$ of molten agar at $30^{\circ} \mathrm{C}$. The underivatized TLC plate was placed in square petri dishes and wet cotton wool was kept besides the petriplates to keep the surroundings moist and prevent drying of bacterial agar suspension.

6 Bacterial agar suspension was spread onto the underivatized TLC plate and was allowed for 30 minutes to solidify. The plates were placed in an incubator at $37^{\circ} \mathrm{C}$ for 24 hours.

7 After the incubation, the TLC plate was uniformly sprayed with $0.2 \%$ of methyl thiazoyltetrazolium (MTT) using ethanol. The active antibacterial compounds formed clear zones of inhibition against pink colored back ground of bacterial growth. The formation of pink colour is due to formazans formed by bacterial dehydrogenases.

8 The inhibition zones were compared with chromatographic Retention factors (Rf) of derivatized TLC plate and bioactive spots/bands were located.

\section{B. Bioautography using DPPH as detection reagent}

$4 \mathrm{mg}$ of DPPH (2,2-diphenyl-1-picrylhydrazyl radical) reagent was dissolved in $50 \mathrm{ml}$ of methanol $(80 \mu \mathrm{g} / \mathrm{ml})$ and filled into the sprayer.

The derivatized and underivatized TLC plates were produced using the same method as mentioned in the above procedure. The underivatized TLC plate was sprayed with DPPH solution and allowed todevelop for 30 minutes.

The Free-radical scavengers/antioxidant spots appeared as cream/yellow against a purple background on the TLC plate. These spots were marked and $\mathrm{Rf}$ values were noted down after comparing them with the reference derivatized TLC chromatogram.

\section{Isolation and purification of bioactive compounds}

The isolation of bioactive fractions was carried out by column chromatography using silica gel (Kalimuthu et al., 2011). Aglass column of $5 \mathrm{~cm}$ diameter and 70 $\mathrm{cm}$ length was packed with the activated $400 \mathrm{~g}$ silica gel slurry (silica gel was dried at $100^{\circ} \mathrm{C}$ with mesh size 60-120; Merck, India) dissolved in petroleum ether. The crude extract (10 gram) of each selected sample was dissolved in minimum quantity of toluene and ethyl acetate for polar and non-polar solvents respectively, followed by adsorbed onto $20 \mathrm{~g}$ of silica gel, the respective solvents were allowed to evaporate and then the silica bound sample was placed at the top of the already packed silica gel column. The mobile phase was allowed to elute the column using increasing polarity in different ratios and fractions were collected, evaporated using rotary evaporator at controlled temperature of $40^{\circ}-50^{\circ} \mathrm{C}$. The identity of the fractions was examined by TLC on silica gel coated aluminum sheets $\mathrm{UV}_{254}$ (Macherey-Nagel GmbH \& Co. Duren Germany). The developed plate was dried, exposed to iodine vapors (Spots marked) and finally derivatized with anisaldehyde reagent (10 $\mathrm{mL}$ sulfuric acid + ice-cooled mixture of methanol and $20 \mathrm{~mL}$ acetic acid $+1 \mathrm{mLanisaldehyde)}$.

Fractions that showed the same UV-Vis spectrum (Canell.,1998) as well as same TLC development profiles (color and Rf) were pooled together and concentrated to dryness under reduced pressure using rotary evaporator. Some of the extracts and active column sub-fractions were purified using preparative pre-coated TLC plates of 20X20 cm (Analtech, Inc. for glass plates and Macherey-Nagel $\mathrm{GmbH} \& \mathrm{Co}$. Duren Germany for AluminumBacked UV ${ }_{254}$ TLC Sheets) using bioautographic approach. The experiment was repeated several times till the purity of the compound was assured by aiming that compound is present as a single spot in the collected bioactive fractions or scrapped bioactive spots. All the scrapped spots were collected and dissolved in highly soluble solvents. The solution was subjected to centrifugation so that the associated silica gel will form the pellet and supernatant was separated, solvent evaporated using rotary evaporator. The physical properties of purified compounds were noted down e.g. colour, solubility $\& \mathrm{R}_{\mathrm{f}}$ values.

\section{Structural Elucidation of Bioactive Compounds}

The purified compounds were characterized for structural elucidation using combined spectral data of various hyphenated techniques (UV-Vis, FT-IR, NMR- 1HNMR, ${ }^{13}$ CNMR, MS-MS) as well as by comparison with previous literature data. The UV-Vis absorbance of the isolated phytocompounds was determined using UV-Vis spectrophotometer (Chemito Technologies, India) using chloroform, ethanol or methanol.Prior to measurement a blank sample of respective solvents were used and the 
system automatically subtracted spectrum of it from the sample spectrum.

The determination of various functional groups were done by FT-IR technique (Perkin Elmer, MA, USA) in the range of $400-4000 \mathrm{~cm}^{-1}(\mathrm{KBr})$ at Central Instrumentation Laboratory- Punjab university, Chandigarh, India. NMR was done using BRUKERAVANCE II400 NMR SPECTROMETER (Karlsruhe, Germany) at frequency of $400 \mathrm{MHz}$, temperature of $298.0 \mathrm{~K}$ to record chemical shifts $(\delta)$ and TMS (Tetramethylsilane) was used as internal standard. The analysis was done at NMR Research Centre, Indian Institute of Science, Bangalore. The samples were prepared by dissolving DMSOd6 and NMR chemical shifts were given in ppm.

The mass spectrum analysis of the isolated compounds was done at SAIF (Sophisticated Analytical Instrumentation Facility) Punjab University, Chandigarh, India using Waters, JEOL GC-Mate II mass spectrometer (Agilent Technologies). The details of liquid chromatography technique used were- separation module: Alliance 2795 (Waters), C18 column (dimensions of $100 \times 2.1$ $\mathrm{mm}$, particle size of $5 \mu \mathrm{m}$ ), injection Volume: $20 \mu \mathrm{L}$, flow rate: $0.4 \mathrm{ml} / \mathrm{min}$, mobile phase used as methanol: water (80:20 ratio). The various mass spectroscopic conditions used in mass spectrometer (Waters, Micromass Q-TOF micro) were as; ionization: Electro spray (ES), resolution-5000, source temperature: $110^{\circ} \mathrm{C}$, desolvation gas: $550 \mathrm{Lts} / \mathrm{Hr}$, Cone Gas: 25 Lts/Hr, desolvation Temperature: $300^{\circ} \mathrm{C}$, capillary voltage: $3000 \mathrm{~V}$, Cone Voltage: $30 \mathrm{~V}$ and collision energy: $4 \mathrm{v}$.

\section{Evaluation of biological activities of isolated compounds}

\section{Antimicrobial activity}

Antibacterial activity of isolated compounds were carried out by using agar well diffusion method as described by Perez et al., 1990 and was explained earlier during preliminary antimicrobial activity of crude extracts. The compounds were dissolved in DMSO in different concentrations i.e. 50, 75 and 100 $\mathrm{mg} / \mathrm{ml}$ for crocins; 50, 75 and $100 \mu \mathrm{g} / \mathrm{ml}$ for (6E)-6Hexadecenoic acid and 50, 75 and 400, 450, 500 and $550 \mu \mathrm{g} / \mathrm{ml}$ for dotriacontanoic acid. A total of $50 \mu \mathrm{l}$ of respective compounds were added to each well.
Antioxidant activity:

The antioxidant activity of isolated compounds was tested using TLC based qualitative assay described by Sarker et al., 2005 with little modifications. Briefly, respective compounds were applied on TLC plates as a spots using capillary tubes at the concentration of $100 \mathrm{mg} / \mathrm{ml}$. The plates were dried, immersed in $0.2 \%$ of DPPH solution in methanol and left for half an hour. The appearance of white/yellow spots against a purple background indicates antioxidant activity.

\section{Anticancer activity:}

The method used for determination of cytotoxicity studies of sample extracts was same as described during preliminary anticancer activities of crude extracts (Francis and Rita, 1986). The percentage growth inhibition was calculated using the following formula and the concentration of test sample needed to inhibit cell growth by $50 \% \quad\left(\mathrm{IC}_{50}\right)$ values was generated from the dose-response curves for both the cell lines.

$\%$ Growth Inhibition $=100-\frac{\text { Mean OD of individual test group }}{\text { Mean OD of control group }}$

\section{STATISTICAL ANALYSIS}

All the measurements were done in triplicates and results are expressed as mean $\pm \mathrm{SD}$. The analysis of variance was performed (ANOVA) by using Origin9 software (OriginLab Corporation, Northampton MA, USA) and Graph Pad Prism 5.01 (Graph Pad Software, San Diego, CA, USA). P values $<0.05$ were considered statistically significant and $\mathrm{P}<0.01$ considered as very significant.

\section{RESULTS AND DISCUSSION}

The compound was isolated from methanol leaf extract of Sambucus wightiana. The purified compound appeared as pale yellow with solublility in methanol, ethanol, water and DMSO. The molecule was found weighed as $9 \mathrm{mg}\left(\mathrm{R}_{\mathrm{f}}=0.18\right.$; Mobile phaseethyl acetate: isopropanol: water in 65:25:10 ratio). The structure elucidation was done tentatively proposed based on observed spectroscopic data (UVVis, FT-IR, NMR and MS-MS) and correlating results with the literature data. UV/Vis spectrum of the isolated compound has showed various absorption bands (Fig.1) at $\lambda \max$ at $224 \mathrm{~nm}$, at $\lambda \max 275 \mathrm{~nm}$, at $\lambda \max 251 \mathrm{~nm}, 302 \mathrm{~nm}, 322 \mathrm{~nm}$. 
The compound in its IR spectrum exhibited a broad absorption band at $3434 \mathrm{~cm}^{-1}$ to indicate the presence of a hydroxyl group, $2992 \mathrm{~cm}^{-1}$ for $\mathrm{C}-\mathrm{H}$ group, 1739 $\mathrm{cm}^{-1}$ to show the presence of a carbonyl group, 1446 and $1375 \mathrm{~cm}^{-1}$ for $\mathrm{C}-\mathrm{H}$ bending frequency, $1069 \mathrm{~cm}^{-1}$ for the C-O group (Fig.2).

In the ${ }^{1} \mathrm{H}-\mathrm{NMR}$ spectrum of the compound exhibited signals at $\delta 0.851-0.884 \mathrm{ppmppm}$ as a singlet for three protons indicating for the presence of a terminal methyl group, at $\delta 1.287$ as a broad singlet for a long chain of methylene protons and at $\delta 2.5$ as a multiplet for four protons (methylene protons $\alpha$ and $\beta$ to the carbonyl group).The ESI positive mode mass spectra exhibited a molecular ion at $\mathrm{m} / \mathrm{z} 481.43[\mathrm{M}+\mathrm{H}]^{+}$ion (Fig.3-4).

The spectral data results (UV-Vis, IR, ${ }^{1} \mathrm{H}-\mathrm{NMR}$ and LC-MS/MS) of current study was found in close correlation with previously reported literature data on lacceroic acid or dotriacontanoic acid (Kalimuthu et al., 2011). Therefore, the compound was tentatively proposedto be dotriacontanoic acid (Fig.6) also known as lacceroic acid or n-dotriacontanoic acid with molecular formula and molecular weight as $\mathrm{C}_{32} \mathrm{H}_{64} \mathrm{O}_{2}$ and 480.84 respectively (Kalimuthu et al., 2011; Gutierrez et al., 2008; Rezanka and Sigler, 2009). The isolation and characterization of this compound was reported for the first time by this study from Sambucus wightiana of Kashmiri Himalaya.

Dotriacontanoic acid or lacceroic acid from methanol extract showed antibacterial activity against E.coli (Table 1; Fig.5). The inhibitory zones were showed by the compound at concentration of $500 \mu \mathrm{g} / \mathrm{ml}$ and $550 \mu \mathrm{g} / \mathrm{ml}$ with zones of inhibition as $9.5 \pm 0.5 \mathrm{~mm}$ and $10.4 \pm 0.6 \mathrm{~mm}$ respectively. However, no antibacterial activity was reported at tested concentration of $400-450 \mu \mathrm{g} / \mathrm{ml}$. From our results, it was found that MIC value against E.coli is greater than $450 \mu \mathrm{g} / \mathrm{ml}$ and minimal inhibitory zone was observed at $500 \mu \mathrm{g} / \mathrm{ml}$ concentration. The results were found statistically significant $(p$ value $<0.05)$.

The sensitivity of lacceroic acid against different bacterial strains such as Escherichia.coli, Pseudomonas aerogenosa, Salmonella paratyphiand Vibrio cholerae has been reported by an earlier study (Kalimuthu et al., 2011). More zone of inhibition was found by current study against E.coli $(10.4 \pm 0.6 \mathrm{~mm}$ ) at lower concentration $(500 \mu \mathrm{g} / \mathrm{ml})$ as compared to previous study by Kalimuthu et al., 2011 with zone of inhibition as $5 \mathrm{~mm}$ at $600 \mu \mathrm{g} / \mathrm{ml}$ concentration. The probable reason for more activity by this study could be because well diffusion method of antibacterial activity has been found more sensitive as compared to disc diffusion method (Valgas et al., 2007).

Naturally occurring oils, spices, herbs etc. could be used against food spoiling pathogens such as Bacillus cereus and E.coli (Dhanukar et al., 2000). Some of the previous researchers have reported that $S$. wightania was traditionally being used as a medicine to treat stomach disorders studies (Kaul, 1997) which could be due to its activity against food poisoning organisms. The strong antibacterial activity of dotriacontanoic acid of Sambucus wightiana origin could find its space in the field of food and pharmaceutical industry as an antimicrobial agent.

The compound was also tested against DPPH free radical using bioautography technique and there was no antioxidant activity. This could be because, antioxidant activities are not majorly attributed directly to the fatty acids (Tardif and Bourassa, 2012). Furthermore, methanol crude extract of S.wightiana did not show any anticancer activity during preliminary analysis against MCF-7 cell line $\left(\mathrm{IC}_{50}>\right.$ 1000) and many antioxidants could act as anticancer agents (Alhakmani et al., 2013). Due to these reasons, no anticancer activity of dotriacontanoic acid was tested in the current study. However, more number of biological activities of this compound could be tested in future studies so as to validate its medicinal properties further. The natural products either in the form of standardized crude extracts or pure isolated compounds gives an opportunity for development of bioactive lead compounds for treatment against infectious diseases and are playing an important role in health care. It is very essential to isolate bioactive active compounds from the plant species which might be used directly to treat certain diseases or could act as structural analogue or a raw material to treat different diseases (Veeresham, 2012). Also, appearance of resistance towards synthetic drugs against dangerous microbes and advent of new diseases will provide an option to use medicinal and aromatic (MAP's) as a preferred option to act as source for new lead compounds. The production of reactive oxygen species is triggered usually by environmental stress, hydrogen hydroxyl radicals which could cause different diseases and addition of antioxidants decreases oxidation rate which ensures controlled regulation of ROS generation. However, it is not always safe to use the crude extracts especially 
from unstandardized plants which might contain constituents which have harmful effects on health e.g. a Chinese plant, Aristolochia fangch contains aristolochic acids which are toxic to kidneys and carcinogenic too.

In conclusion, this study has attempted to isolate, purify and characterize bioactive compounds from alternative plant sources and this could help to avoid the chances of any health problem because of unstandardized crude plant based extracts. Also, the knowledge of medicinal and aromatic plant based bioactive compounds is very vital to define the standardized herbal extracts and more number of economically important plants needs to be explored phytochemically . This is because the phytochemical composition of plant species varies with geographical location, environmental conditions etc. expectantly, the results of current study could add an additional towards formulation of new, safe and effective bioactive phytocompounds from cheap plant sources with pharmaceutical, food and cosmaceutical importance. It is therefore expected that future toxicological studies such as pre-clinical and clinical trials could be initiated on these molecules which could pave a way for them to enter into formulation, drug developmental stages and subsequent entry into the pharmaceutical industry (Rates et al., 2001).

\section{ACKNOWLEDGMENTS}

The current work was supported by grant from Sharmila Pharma, Thanjavur, Tamil Nadu and authors are highly obliged.

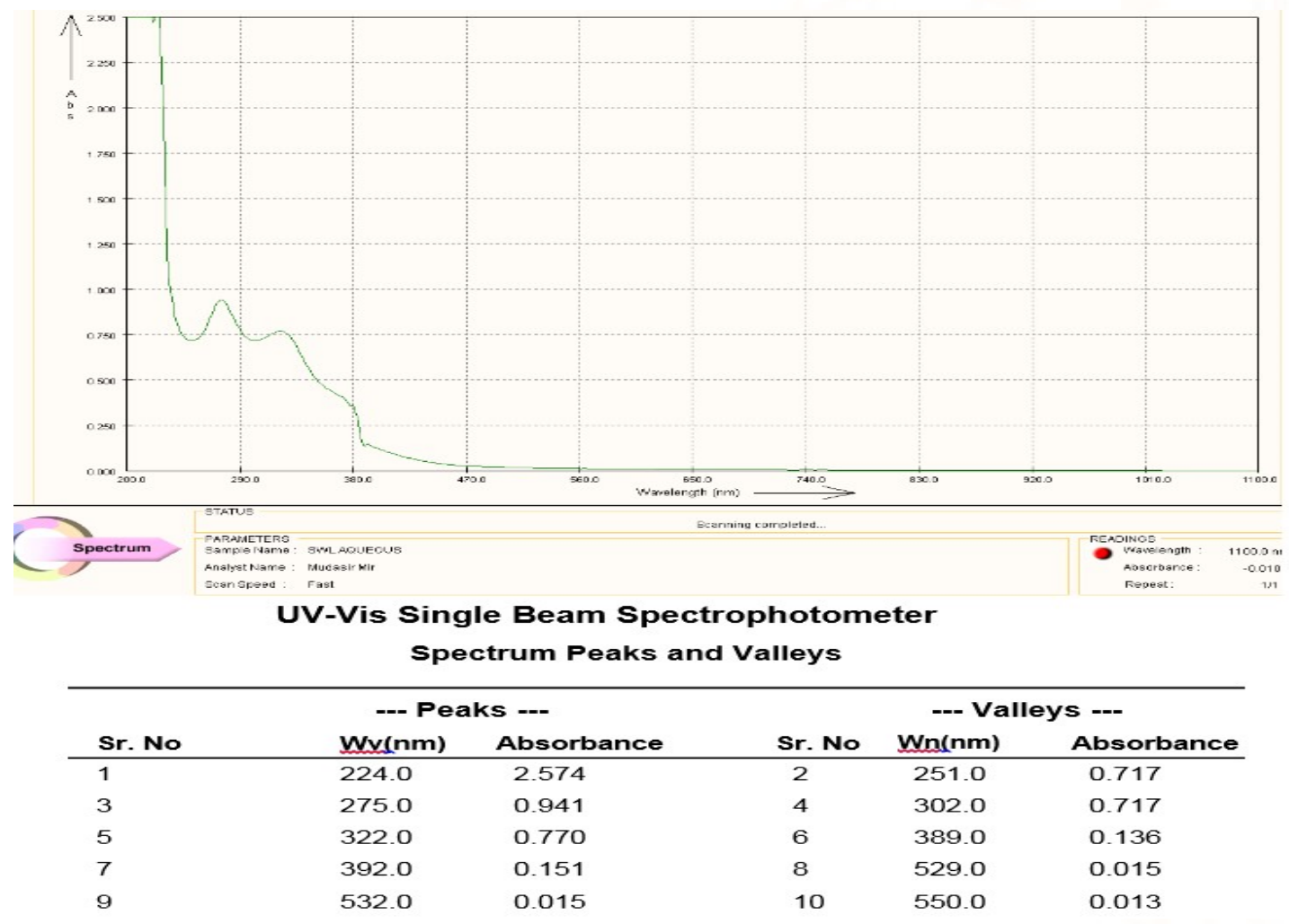

Fig 1. Uv-Vis spectrum of Dotriacontanoic acid 


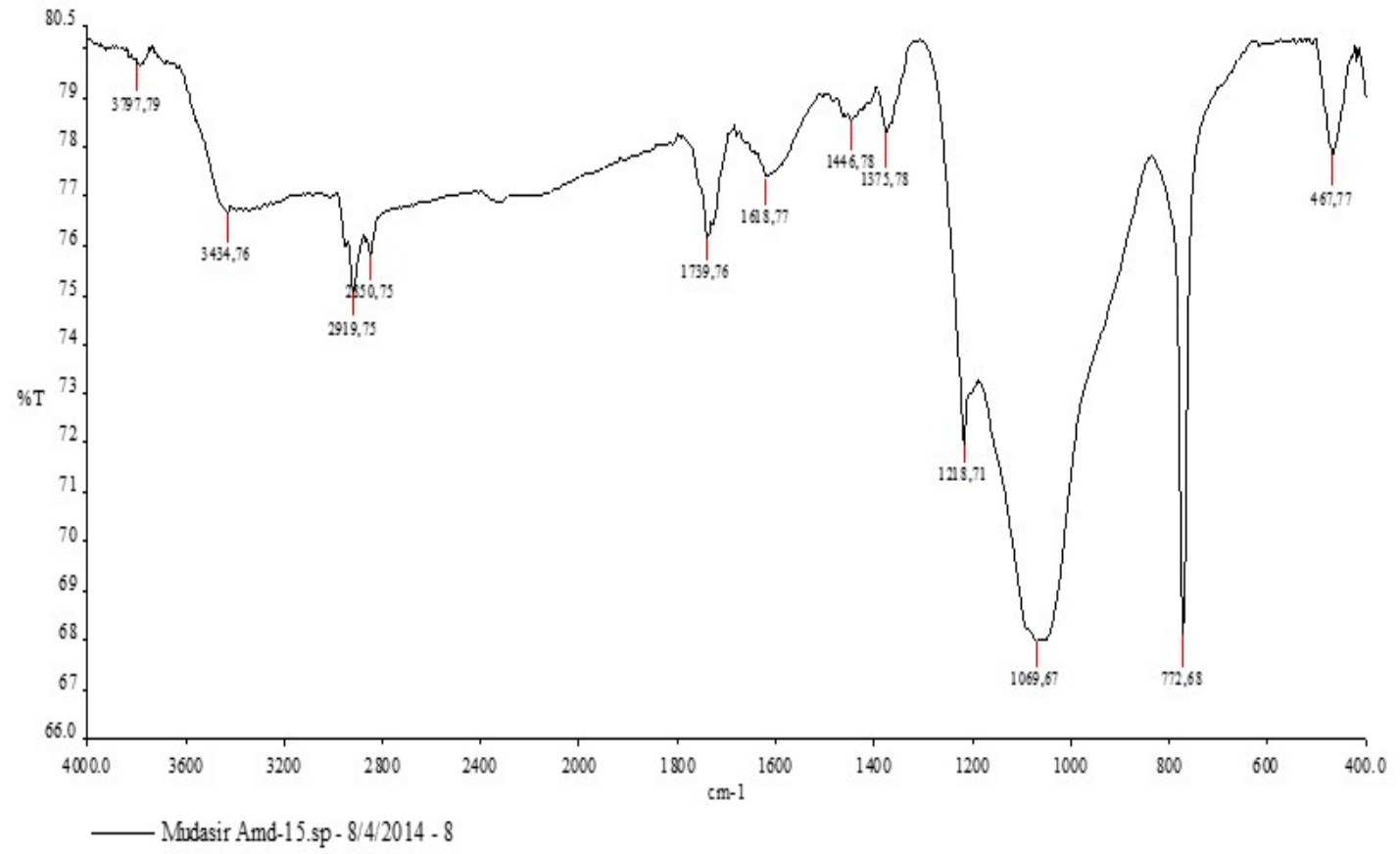

Fig 2. FT-IR spectrum of Dotriacontanoic acid

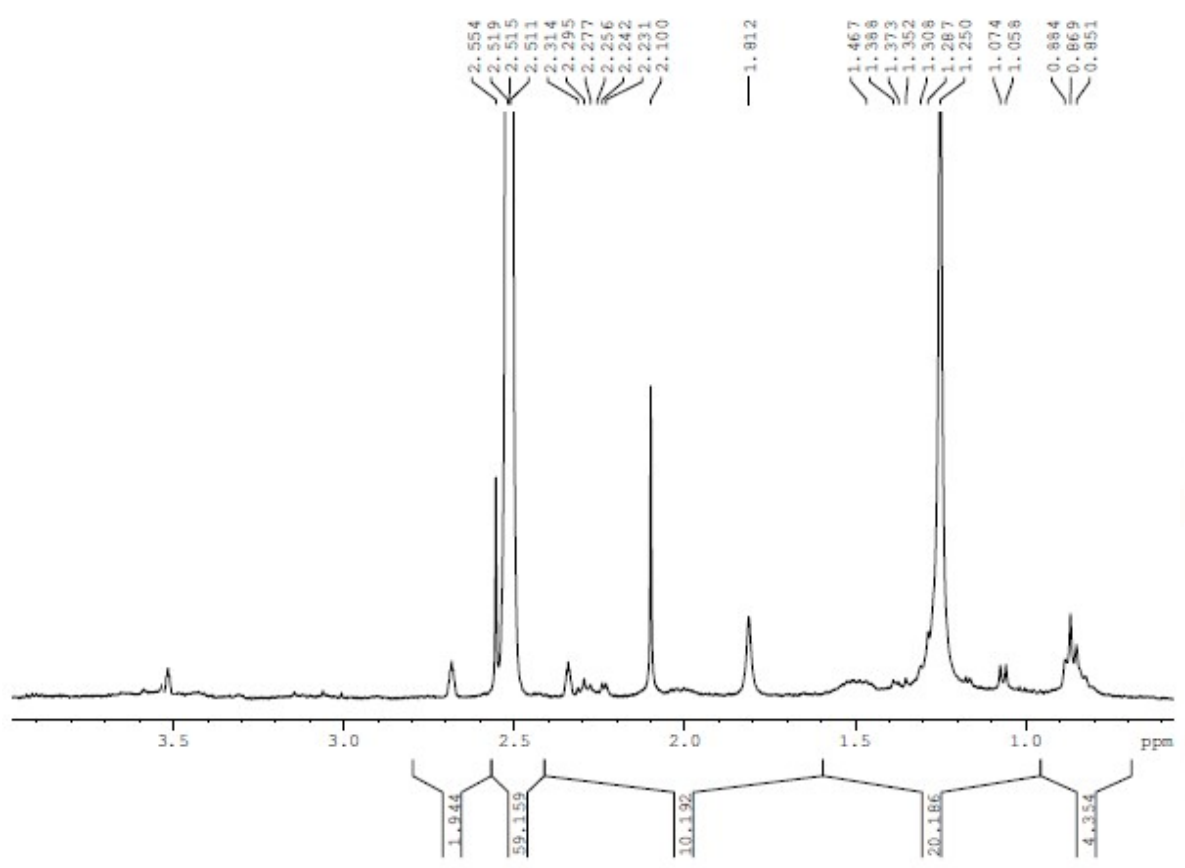

Fig 3. ${ }^{1}$ HNMR of Dotriacontanoic acid 


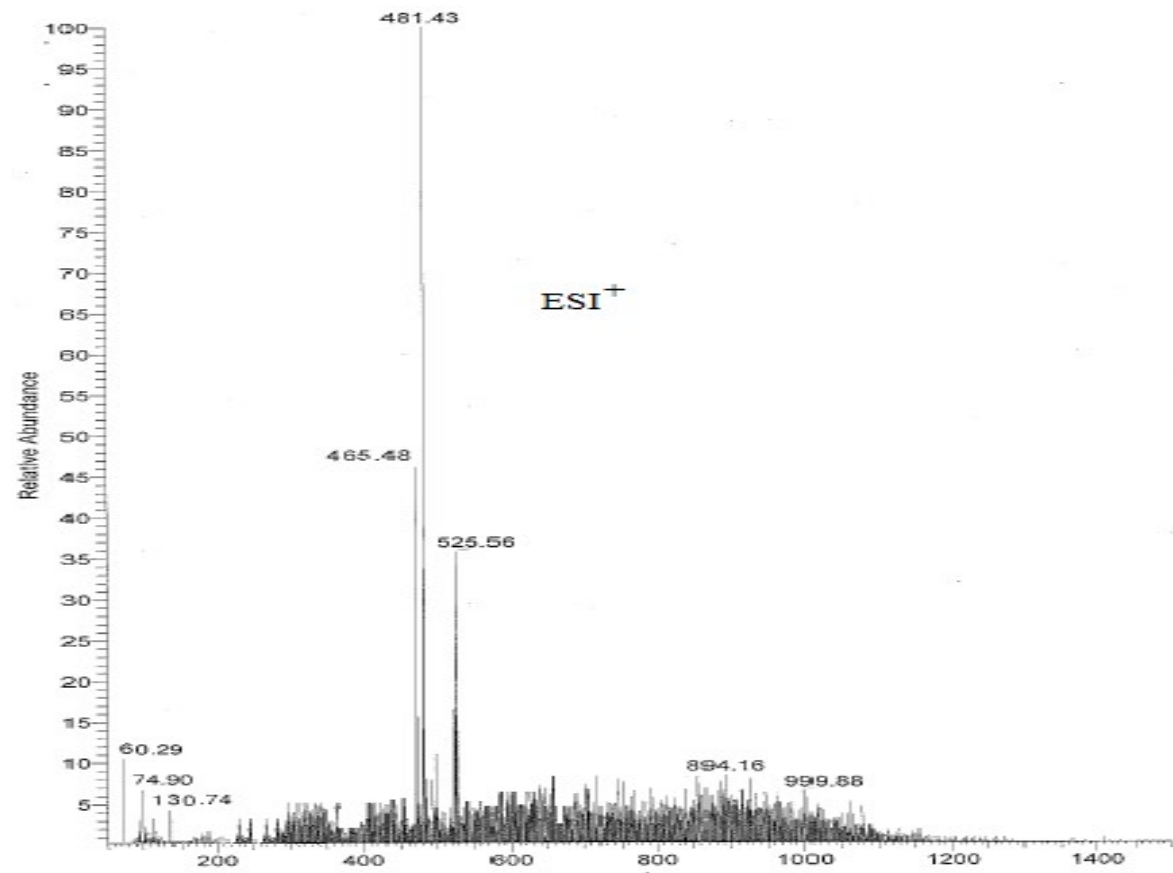

Fig 4.Mass spectrum of Dotriacontanoic acid (ESI)

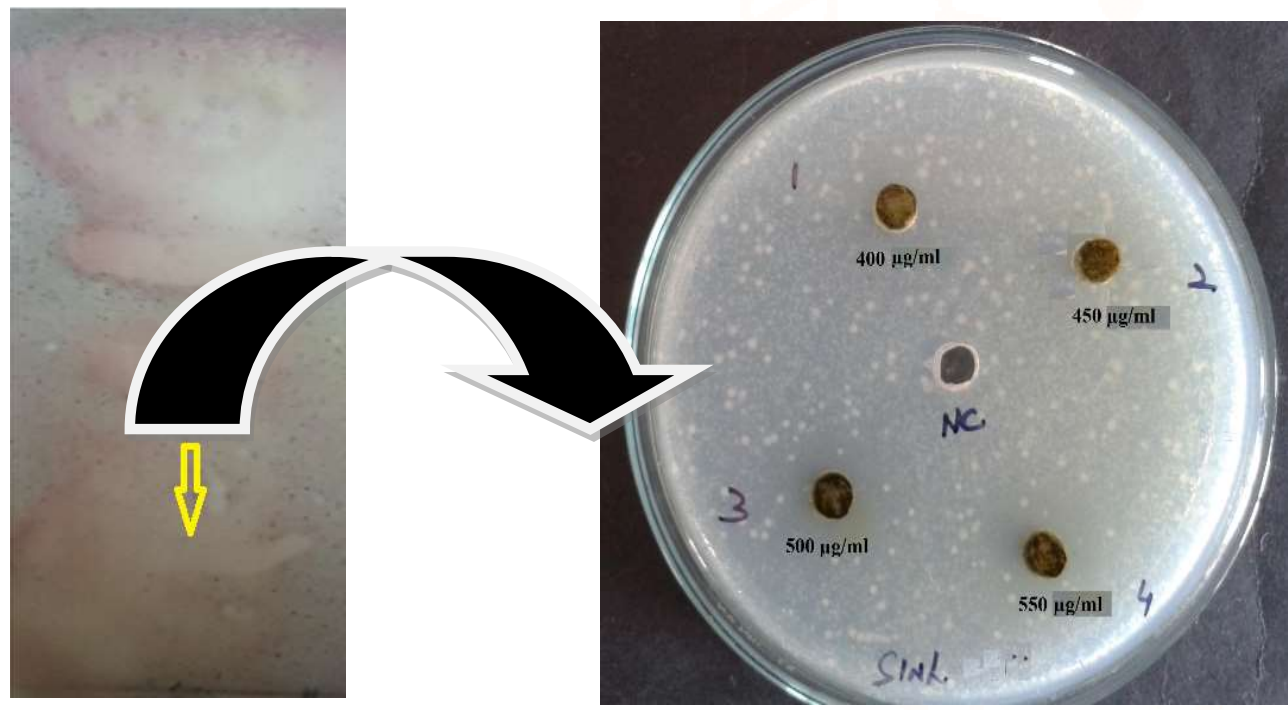

Fig 5. Bioautography based antibacterial activity of Dotriacontanoic acid against $E$.coli. 
International Journal of Trend in Scientific Research and Development (IJTSRD) ISSN: 2456-6470

Table 1. In-vitro antibacterial activity of

\section{Dotriacontanoic acid against $E . c o l i$.}

\begin{tabular}{|c|c|c|}
\hline S.No. & Conc. $(\mu \mathrm{g} / \mathrm{ml})$ & $\begin{array}{c}\text { Zone of Inhibition } \\
(\mathbf{m m})\end{array}$ \\
\hline $\mathbf{1}$ & 400 & NI \\
\hline $\mathbf{2}$ & 450 & $8.3 \pm 0.2$ \\
\hline $\mathbf{3}$ & 500 & $9.5 \pm 0.5$ \\
\hline $\mathbf{4}$ & 550 & $10.4 \pm 0.6$ \\
\hline
\end{tabular}

Fig 6. Structure of isolated Dotriacontanoic acid

\section{V.REFERENCES}

1) Polunin, O. and Stainton, A. 1984. Flowers of the Himalaya. Oxford Univ Press, Delhi.

2) Kaul, M.K. 1997. Medicinal Plants of Kashmir and Ladhak. Indus PublisihningCo.,New Delhi, 144.

3) Sharma, R. 2003. Medicinal Plants of India, an encyclopedia. DayaPublisihinghouse, Delhi,221222.

4) Khattak, S., Rehman, S.U., UllahShah, H., Khan, T. and Ahmad, M. 2005. In vitro enzyme inhibition activities of crude ethanolic extracts derived from medicinal plants of Pakistan. Nat. Prod. Res. 19, 567-57.

5) Vidyarthi, O.P.S. 2010. Forest Flora of Kashmir. Working Plan Circle, Jammu and Kashmir Forest Department, 34.

6) Stewart, J.L.1869. Punjab plants, Botanical and Vernacular Names, and Uses. Government press, public works department, Lahore.23.

7) Ford, C.E. 1938. A contribution to a cytogenetical survey of Malvaceae. Genetica 20:431.

8) Ballabh, B., Chaurasia, O.P., Ahmed, Z., Singh, S.B 2008.Traditional medicinal plants of cold desert Ladakh-Used against kidney and urinary disorders. J Ethnopharmacol118, 331-339.

9) Bhawna, Dave S.N.B., 2010. In Vitro Antimicrobial Activity of Acacia catechu and Its Phytochemical Analysis. Indian J Microbiol .4, 369-374.
10) John, P., Melnyk, Sunan, W., Marcone, M.F., 2010. Chemical and biological properties of the world's most expensive spice: Saffron. Food Res Int. 43, 1981-1989.

11) Patra, J.K., S. Gouda, S., Sahoo, S.K., Thatoi, H.N., 2012. Chromatography separation, 1H NMR analysis and bioautography screening of methanol extract of Excoecaria agallocha L. from Bhitarkanika, Orissa, India. Asian Pac $J$ Trop Biomed. S50-S56.

12) Sarker, S.D., Latif, Z., Gray, A.I., 2005. Methods in Biotechnology, Natural Products Isolation. Humana Press Inc. New Jersey, USA.

13) Alwash, M.S., Ibrahim, N., Ahmad, W.Y., 2013. Bio-guided study on Melastoma malabathricum linn leaves and elucidation of its biological activities. American Journal of Applied Sciences. 8, 767-778.

14) Canell, R.J.P. 1998. Natural Products Isolation.Humana Press, Totowa, New Jersey, USA.

15) Reich, E., 2006. High-performance thin-layer chromatography for the analysis of medicinal plants. Thieme Medical Publishers, Inc.333 Seventh Ave. New York, NY.

16) Sule, A., Ahmed, Q.A., Abd, O., Samah., Omar, M.N., Hassan, N.M., Laina Zarisa M. Kamal, L.Z.M., Yarmo, M.A., 2011. Bioassay Guided Isolation of Antibacterial Compounds from Andrographis paniculata. Am J Applied Sci. 6, 525-534.

17) Kalimuthu, S., Latha, S., Selvamani, P., Rajesh, P., Balamurugan, B., Chandrasekar, T.M., 2011. Isolation, Characterization and Antibacterial Evaluation on Long Chain Fatty Acids From Limnophila polystachya Benth. Asian J. Chem. 23, 791-794.

18) Perez, C., Pauli, M., Bazerque, P., 1990. An antibiotic assay by the agar well diffusion method. Acta Biol Med Exp. 15, 113-115.

19) Francis, D. and Rita, L. 1986. Rapid colorometric assay for cell growth and survival modifications to the tetrazolium dye procedure giving improved sensitivity and reliability. J. Immunol.89: 271277.

20) Gutierrez, A., Rodriguez, I.M., Rio. J.C.D.2008. Chemical composition of lipophilic 
extractivesfrom sisal (Agave sisalana) fibers. Ind Crops Prod. 2 8, 81-87.

21) Rezanka, T., Sigler, K., 2009. Odd-numbered very-long-chain fatty acids from the microbial, animal and plant kingdoms. Progress in Lipid Research. 48, 206-238.

22) Valgas, C., Souza, S.M., Smania, A.F.A., Artur, S.J. 2007. Screening methods to determine antibacterial activity of natural products. Braz. J. Microbiol.38, 369-380.

23) Dhanukar, S.A., Kulkarni, R.A. and Rege, N.N. 2000 . Pharmacology of Medicinal plants and Natural Products. Indian $J$ Pharmacology. 32:S81-S118
24) Tardif J.C., Bourassa M. G., 2012. Antioxidants and Cardiovascular Disease. Springer Science \& Business Media.

25) Alhakmani, F., Kumar, S. and Khab, S.A. 2013. Estimation of total phenolic content, in-vitro antioxidant and anti-inflammatory activity of flowers of Moringaoleifera. AsianpacJ.Trop Biomed. 8, 623-627.

26) Veeresham, C., 2012. Natural products derived from plants as a source of drugs. J Adv Pharm Technol Res. 3, 200-2001.

27) Rates, S.M.K., 2001. Plants as source of drugs. Toxicon. 39, 603-613. 